\title{
Will Marriage Lead to Poverty? Research on the Influence of Marriage on Chinese Family Poverty
}

\author{
Yi Zhou \\ School of Public Administration and Emergency Management, Jinan University, Guangzhou, China \\ Email: lijieee201314@163.com
}

How to cite this paper: Zhou, Y. (2018) Will Marriage Lead to Poverty? Research on the Influence of Marriage on Chinese Family Poverty. Open Journal of Social Sciences, 6, 135-146. https://doi.org/10.4236/jss.2018.68011

Received: July 16, 2018

Accepted: August 20, 2018

Published: August 23, 2018

Copyright $\odot 2018$ by author and Scientific Research Publishing Inc. This work is licensed under the Creative Commons Attribution International License (CC BY 4.0).

http://creativecommons.org/licenses/by/4.0/

\section{(c) (i) Open Access}

\begin{abstract}
In this paper, we use the cross-sectional data from the China Family Panel Survey (CFPS) in 2014 and use logit model and OLS regression model to analyze the effects of marriage events and marriage consumption on household poverty. The empirical research results of this article once again verify the existence of the phenomenon of "marriage lead to poverty". Specifically, in contrast to families without a marriage event, if the family has a marriage event, the probability of the family becoming a poor household will increase by $28.7 \%$. The abnormally high marriage consumption is actually the phenomenon of exploitation between families and between generations. The serious marriage burden it brings to the family cannot be ignored. In view of this, we must actively guide people to establish a correct view of marriage and formulate relevant laws and regulations in order to get rid of this bad customs of marriage.
\end{abstract}

\section{Keywords}

Marriage Leads to Poverty, Poverty Rate, Degree of Poverty

\section{Introduction}

In recent years, with China's social and economic development, gender imbalance, and a large number of women's marriage moves, marriage costs and bride price of marriage in some parts of China, especially in impoverished rural areas, have skyrocketed. For example, the bride price of marriage of Guizhou rose from 20,000 yuan to RMB 88,000 and "three gold jewelry"; the bride price of marriage of Shaanxi's from 30,000 yuan and "three gold jewelry" and "three silver jewelry" rose to 100,000 yuan, "three gold jewelry" and a car'. In typical places, a house, a 'https://news.china.com/socialgd/10000169/20170221/30270622_all.html 
car, and "three golds" have become the standard for marriage. In a country such as China, which exemplifies the patrilineal system and the system of living with the husband, there are deep traditions and cultural foundations for weddings and the bride price of marriage. Since the Zhou Dynasty from 3000 years ago, the bride price as an integral part of the marriage behavior and marriage culture model is an integral part of the marriage ceremony. After thousands of years of social development, it is enduring and the phenomenon of bride price is very common. The rate of bride price of marriage in China exceeds about $90 \%[1]^{2}$. In addition to the extraordinarily bride price of marriage, wedding spending, including banquets and ceremonies, have also shown a trend of soaring. This is like a ruthless barrier that let many young men who are at the age of marriage and love be able to marry. Reports also pointed out that China has emerged a new phenomenon of poverty- "marriage leads to poverty", tens of thousands or even hundreds of thousands of "bride price/wedding", have become a heavy burden on ordinary families ${ }^{3}$. Once we borrowed money to get married and repay the debt in ten years, the family was caught in the dilemma of "marriage leads to poverty for decade". In order to stop the winds of astronomical prices, the National Health and Family Planning Commission, the Central Civilization Office and other departments stressed: "The governments at all levels will strengthen their guidance, advocating simple marriage and opposition to arranged marriages, illegal early marriages, large-scale operations of marriages, and obtaining property through marriage." It also directly criticized the phenomenon of high bride price of marriages, high-profile wedding, and blind comparisons [2].

However, this high amount of gift and competition is still corrupting the social atmosphere, making the pure love to be alienated by money, and the marriage of the children has also become the most extravagant consumption in many families' lives. Even this became a way for some young people to "squeeze" their parents. The concept of poverty due to marriage has been widely accepted by the society. However, most of the relevant studies have been based on qualitative research and case studies of regions or villages, and there is still no reliable argument based on empirical research. Based on this, this paper will use data from the 2014 China Family Panel Survey (CFPS) to verify whether family marriage has affected family poverty through statistical models.

\section{Data and Methods}

1) Sources of data

The research data in this paper comes from the China Family Panel Survey (CFPS) 2014 cross-sectional data provided by the China Social Science Survey Center of Peking University. The baseline survey of the survey was implemented in 2010. In 2012, the project implemented nationwide first-round and

${ }^{2}$ Rural Marriage Survey conducted by Professor Shi Qinghua of Shanghai Jiaotong University (2002, 2003, 2004, 2006)

${ }^{3}$ http://www.sohu.com/a/62378526_116449 
full-sample tracking. 2014 was the third round of the full-sample survey. The questionnaire included family member questionnaires, family economic questionnaires, adult questionnaires, children questionnaires, and village/neighborhood questionnaire. In the later period of data verification, recording verification of suspected observations of some of the numerical variables in the questionnaire to ensure the credibility of the results. At the same time, there is a high degree of consistency between the basic situation of respondents reflected in this survey and the sixth national census data, and the reliability of the data is relatively high.

Since this study is about poverty at the household level, it uses the family economic questionnaires. The questionnaire covers issues such as family living conditions, income, expenses, housing, assets, and important events in 29 provinces. The sample size is 13,946 and the number of variables is 398 .

2) variable settings

\section{Dependent variable: Poverty or not/Poverty}

The dependent variable of this study is "poverty". For the measurement of poverty, this paper adopts the measurement methods of unilateral and multidimensional poverty. The unilateral poverty measurement refers to subjective "economic difficulties" indicators. Questionnaire survey questions are "What is the main difficulty of your family?" If the interviewed family selects "economic difficulties", this article is set as a dummy variable ( 0 - 1 variable). This article is defined as "poverty or not". The data shows that of the 13,946 samples, 5772 of the interviewed households, that is, $41.39 \%$ of the households believe that they have economic poverty.

Multidimensional poverty reflects the incidence of poverty and family poverty and the intensity of deprivation suffered. Firstly, the measurement gets the family's value on each dimension, and then defining a poverty standard for each dimension, according to this standard to identify whether the family is poor in this dimension. This paper combines the relevant technical regulations for each specific indicator of the United Nations Millennium Development Goals, as well as the actual conditions in China and the availability of data to establish the threshold for deprivation of each dimension [3]. Seven indicators other than income poverty were selected (for details, see Table 1). The results showed that $19.82 \%$ of households in China had housing difficulties in 2014; 30.83\% of households did not have access to safe water; $37.51 \%$ of households do not use electricity normally; $48.65 \%$ of households do not have health facilities; $67.40 \%$ of families do not enjoy general durable assets; $11.55 \%$ of households do not receive any form of collective land; $12.96 \%$ of households worry about their children's education. Based on the above seven indicators, this paper will add them up and standardize them to finally obtain an indicator of the "poverty degree" of the family. The greater the value, the deeper the degree of family poverty. In the total sample, the average "poorness" of Chinese families is 0.4732 .

\section{The independent variable}

The first core independent variable in this article is whether there is "marriage" in the family. This includes both male and female marriages, because in 
Table 1. Establishment of deprivation thresholds.

\begin{tabular}{|c|c|c|c|}
\hline No. & Dimensions & Deprivation threshold & $=1$ \\
\hline 1 & Housing & $\begin{array}{l}\text { Children over } 12 \text { years old live in the same room as their parents; } \\
\text { three generations of young and old live in the same room; children of } \\
\text { the opposite sex over the age of } 12 \text { live in the same room; some beds } \\
\text { are set up at night but removed during the day and other housing } \\
\text { problems, with an assigned value of } 1 .\end{array}$ & $19.82 \%$ \\
\hline 2 & Drinking Water & $\begin{array}{l}\text { Cooking water is not mainly from tap water, bottled water/pure } \\
\text { water/filtered water, and its value is } 1 .\end{array}$ & $30.83 \%$ \\
\hline 3 & Health Facilities & $\begin{array}{l}\text { Cannot use indoor or outdoor flush toilets or flush public toilets with } \\
\text { an assigned value of } 1 .\end{array}$ & $48.65 \%$ \\
\hline 4 & Electricity & $\begin{array}{l}\text { In the home without electricity, frequent power outages, or occasional } \\
\text { power outages, assigned a value of } 1 .\end{array}$ & $37.51 \%$ \\
\hline 5 & General Assets & $\begin{array}{l}\text { There are no refrigerators, washing machines, televisions, computers, } \\
\text { mobile phones, and any other asset at home with an assigned value of } \\
1 .\end{array}$ & $67.40 \%$ \\
\hline 6 & Land & $\begin{array}{l}\text { The family is not assigned any form of collective land (such as Cultivated } \\
\text { land, forest land, pastures and ponds, etc.), assigned a value of } 1 .\end{array}$ & $11.55 \%$ \\
\hline 7 & Child Education & $\begin{array}{l}\text { The main difficulty families face is their children's education, with a } \\
\text { value of } 1 .\end{array}$ & $12.96 \%$ \\
\hline
\end{tabular}

some parts of China, daughters need to prepare dowries. This has become an important economic burden for the family. The question in the questionnaire is "Has there been a male in your family getting married in the past 12 months?" Has there been a female in your family getting married in the past 12 months?" Yes, a value of 1 is assigned, and a value of 0 is assigned to no. If the investigator chooses yes, the value is 1 , and if no, the value is 0 . The results showed that among the 13,946 samples, only 257 families had men married, while only 213 families had women married, and 235 families had both men and women married. The sample of analysis in this paper is 705 .

The second core independent variable is the total consumption of marriage in the family, because the commitment of the male and female parties to the payment of marriage is not only reflected in the explicit financial resources, but also the expense of the banquet ceremonies. These are the rigid demands for marriage. Therefore, these should also be included in the total consumption of marriage. According to the data, only males in the family were married and the average total consumption was 53,719 yuan; only females in the family were married and the average total consumption was 20,443 yuan. This shows that in Chinese marriages, the man's family is the main consumer and the poverty impact on his family may be even greater.

\section{Control variables}

In order to obtain the effect of marriage on family poverty, we control other variables that affect family poverty, such as the family's annual income, the household's daily annual consumption, household deposits, financial assets, and the family's community type (residential committee or village committee). Con- 
sidering the influence of regional economy, this paper also controls the regional variables. According to the data, the annual household income in the total sample is 46,836 yuan, the daily household consumption is 34,465 yuan, the household deposit is 24,209 yuan, the value of home financial assets is about $2520 \mathrm{yu}$ an, of which 79.03 percent of the family community types are village committees. Specific variable information is shown in Table 2.

3) analysis method

In the model design, according to the characteristics of the dependent variable to choose, because the dependent variable "poverty rate" is a discrete variable, this article first uses the logit model to examine which factors affect the family become poor households:

$$
P=G(X)=\frac{\exp \left(\beta_{0}+\beta_{1} X_{1}+\beta_{2} X_{2}+\cdots+\beta_{n} X_{n}\right)}{1+\exp \left(\beta_{0}+\beta_{1} X_{1}+\beta_{2} X_{2}+\cdots+\beta_{n} X_{n}\right)}
$$

4) After taking the logarithm reduction, the formula becomes:

$$
\ln [p /(1-p)]=\beta_{0}+\beta_{1} X_{1}+\beta_{2} X_{2}+\cdots+\beta_{n} X_{n}
$$

Assuming $X_{i}$ is a substantially continuous variable, its partial effect on the response function can be obtained by calculating the partial derivative:

$$
G(X) / \partial X=g\left(X_{i}\right) \beta_{i}
$$

$G(X)$ is the joint probability distribution and $g\left(X_{i}\right)$ is the probability density function. Since in the case of logit, $G(X)$ is strictly increasing, there is always $g\left(X_{i}\right)>0$. This partial effect has the same sign as $\beta_{i}$. When $X_{i}$ changes small enough, the above equation can be converted to:

$$
\Delta G(X) \approx\left[g\left(X_{i}\right) \beta_{i}\right] \Delta X_{i}
$$

In the binary response model, $\beta_{i}$ represents the variable of the natural logarithmic value of the occurrence ratio of the dependent variable of household poverty rate when the independent variable changes by one unit each time.

Table 2. Description of variable information.

\begin{tabular}{ccccc}
\hline variable & Mean & Standard deviation & Min & Max \\
poverty or not & 0.4138 & 0.4925 & 0 & 1 \\
degree of poverty & 0.4732 & 0.297 & 0 & 1 \\
Marriage or not & 0.0505 & 0.2191 & 0 & 1 \\
Total consumption of marriage & 49,209 & 61,860 & 8 & 500,000 \\
Total income from marriage & 25,064 & 27,901 & 5 & 350,000 \\
Annual income of household & 46,836 & 42,168 & 0 & 330,000 \\
Annual consumption of household & 34,465 & 35,559 & 0 & 300,000 \\
household deposits & 24,209 & 57,704 & 0 & 500,000 \\
Financial assets & 2520 & 16,741 & 0 & 200,000
\end{tabular}


Second, we use the OLS regression model to analyze the effect of marriage on the degree of poverty of Chinese families.

$$
\text { poor }=\partial+\beta_{k} X_{k}+\varepsilon
$$

Among them, poor is the degree of poverty in the household, i.e., it is an explained variable, a constant term. $\beta_{k}$ is the coefficient of the explanatory variable. $X_{k}$ is a series of explanatory variables affecting the degree of poverty of family, and $\varepsilon$ is a random error.

\section{Analysis of Results}

1) Descriptive statistical analysis

\section{Total wedding consumption in different provinces}

The two national maps of bride price in 2013 and 2017 sparked heated debates, and the obvious regional differences reflected in Figure 1 were widely recognized. The data in this paper also confirms the obvious regional differences in the consumption of marriage. According to the data shown in Figure 1, the consumption of marriage in Nei Menggu is the highest, reaching 160,000 yuan. However, since the province's regional sample is only 1 and it is not representative, so this paper does not consider. From the overall data distribution, the eastern coastal cities of Zhejiang, Jiangsu and Shanghai have the highest level of total consumption of marriage, which is mainly influenced by the economic and social development at the provincial macro level. From the comparison of the differences between the northern and southern provinces, overall, the marriage consumption in the northern provinces ${ }^{4}$ is higher than that in the southern provinces ${ }^{5}$.

This may be explained by the fact that there is a strong clan structure in the rural areas of southern China. It is a united village. The village clan has strong structural and normative power, heavy and balanced intergenerational relations,

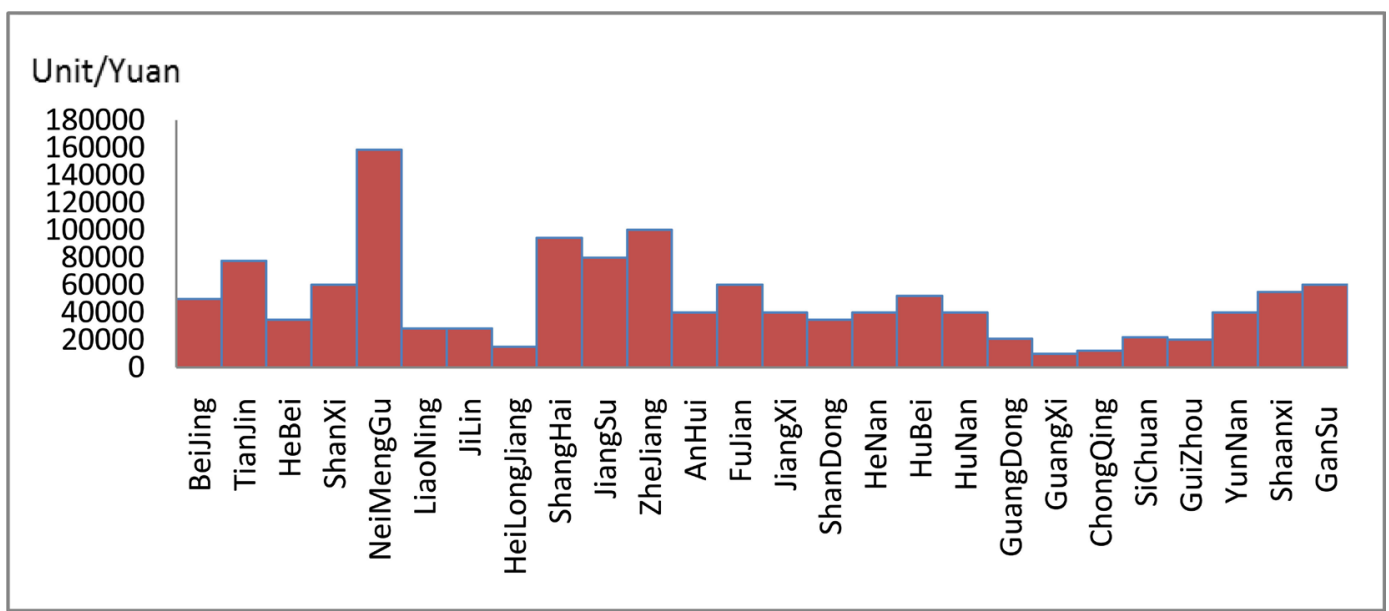

Figure 1. Average of total marriage consumption in each province in China.

${ }^{4}$ Bei Jing, Tian Jin, He Bei, Shan Xi, Nei Meng Gu, Liao Ning, Ji Lin, Hei Long Jiang, Shang Hai, Shan Dong, He Nan, Shaanxi and Gan Su are 736,540 yuan.

${ }^{5}$ Jiang Su, Zhe Jiang, An Hui, Fu Jian, Jiang Xi, Hu Bei, Hu Nan, Guang Dong, Guang Xi, Chong Qing, Si Chuan, Gui Zhou and Yun Nan are 537,000 yuan. 
higher autonomy in marriage, and general competition in the marriage market. The bride price is generally considered to be the hard money for raising daughters and the bride price as the return to parents will not be added without limit, otherwise the reputation will be bad and not recognized, so the rate of increase of the bride price in the southern provinces will not change with the rapid economic development, but will slowly and steadily change. The rural villages in the north belong to split-type villages, and the villages are highly competitive. The villagers' lives are embedded in the village's competition structure and overall value norms. The intergenerational relations are heavy but unbalanced, the marriage autonomy is weak, the marital market competition is fierce and the competitive village social structure makes the bride price of marriage also become an important competition place. Can not afford to pay a high amount of bride price, the son can not get married, are a very faceless thing. The family will also be the object of discussion and rejection by the villagers. This is more serious than debt. The fierce competition in bride price of marriage has not only promoted the rapid increase of bride price, but also exacerbated the exploitation of intergenerational relationships [4].

\section{Poverty situation in different provinces}

As shown in Figure 2 and Figure 3, whether the use of a single-dimensional

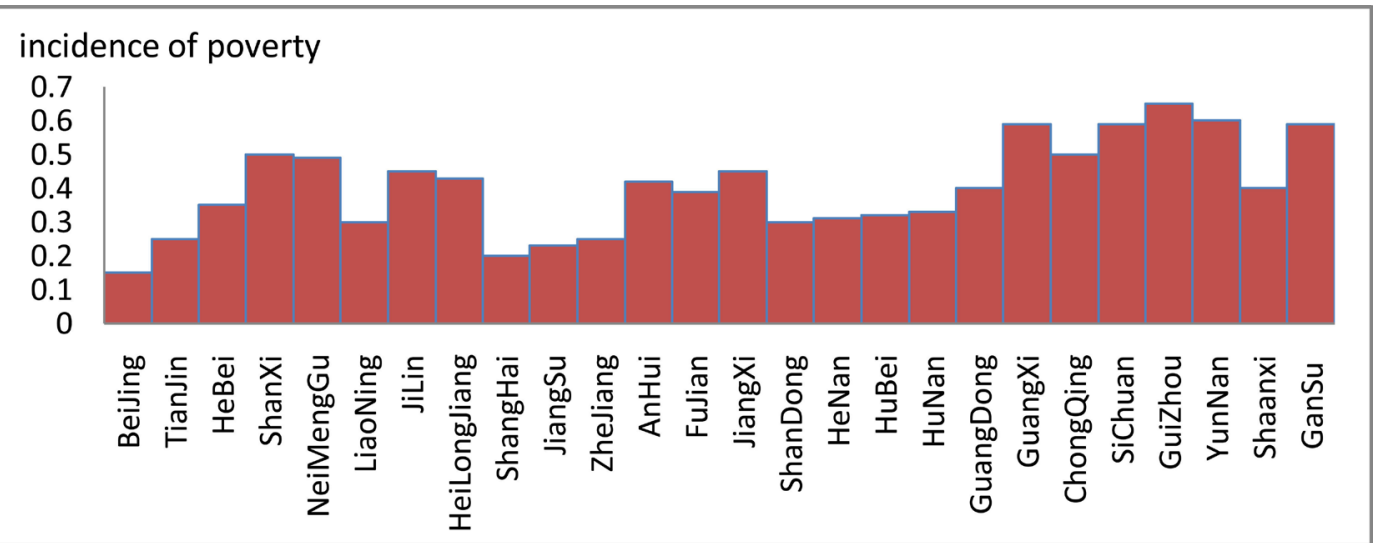

Figure 2. Poverty rates in various provinces in China.

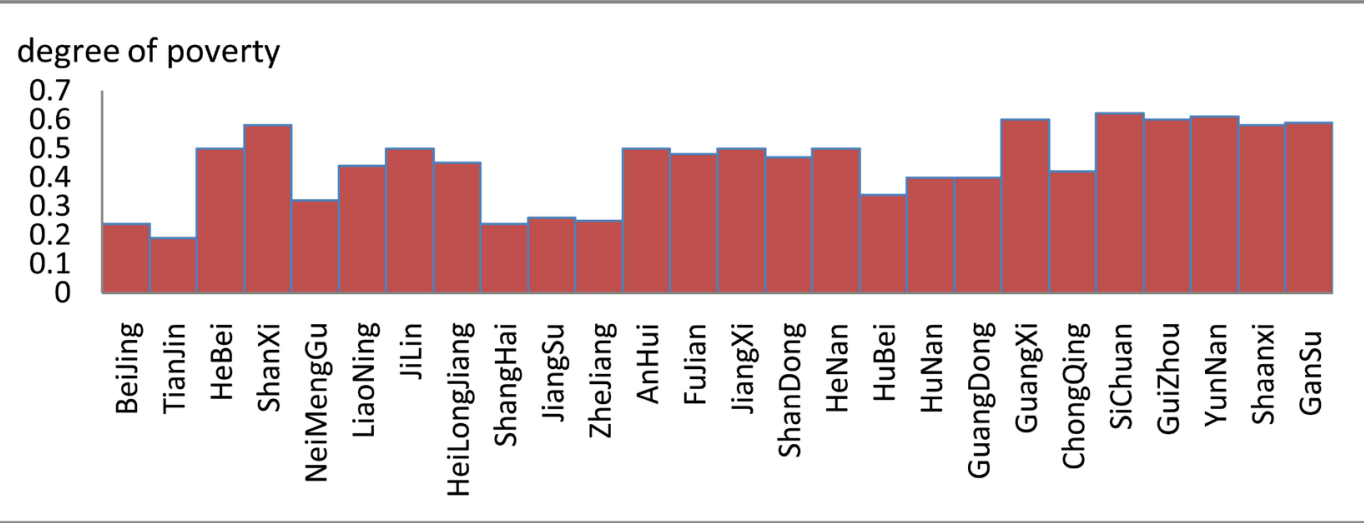

Figure 3. Degree of poverty in various provinces in China. 
economy to measure the incidence of poverty or the use of multi-dimensional poverty indicators to measure the intensity of poverty, the China Family Panel Survey (CFPS) 2014 cross-section data show that the incidence of poverty in China's provinces is basically the same as the poverty intensity in the region, showing the spatial distribution law of "lower in the west and high in the east and decreasing in the number of steps". Areas of high poverty are mainly concentrated in the western provinces and the northeast region; areas of low poverty areas are concentrated in the three major economic belts: the Yangtze River Delta, the Pearl River Delta, and the Bohai Rim (Beijing-Tianjin) region. This data result is basically consistent with previous research findings.

\section{Variable correlation}

When dependent variables and independent variables are analyzed for correlation, it was found that poverty incidence and degree of poverty were negatively correlated with household annual income, household annual consumption, household deposits and financial assets. That is, the higher the household annual income, household deposits, and financial assets, the lower the probability that the family will become a poor family. At the same time, the higher household annual consumption also proves that the family is less likely to be a poor family, but the most relevant variable is the household annual income. The relevance of the core independent variables, namely, "marriage or not" and "poor rate" and "degree of poverty" that we focus on, is not consistent. Positive correlation between marriage and poverty incidence in the family, that is, when an important event such as marriage occurs in the family, the possibility of families becoming poor households will increase. However, marriage is negatively correlated with the degree of poverty, which means that the poorer families are less likely to have a marriage event shown in Table 3. For more rigorous reasoning, we need to use the regression model to illustrate.

2) Analysis of empirical results

\section{The effect of marriage on the incidence of family poverty}

According to the binary response model, this paper takes the incidence of unidimensional family poverty as the dependent variable. The model (1)-model (2) in Table 4 takes whether there is a marriage event in the family as the core

Table 3. Correlation between variables.

\begin{tabular}{|c|c|c|c|c|c|c|c|}
\hline & $\begin{array}{l}\text { household } \\
\text { annual income }\end{array}$ & $\begin{array}{l}\text { household annual } \\
\text { consumption }\end{array}$ & $\begin{array}{l}\text { household } \\
\text { deposits }\end{array}$ & $\begin{array}{l}\text { financial } \\
\text { assets }\end{array}$ & $\begin{array}{l}\text { poverty } \\
\text { incidence }\end{array}$ & $\begin{array}{l}\text { degree of } \\
\text { poverty }\end{array}$ & married \\
\hline household annual income & 1 & & & & & & \\
\hline household annual consumption & 0.6148 & 1 & & & & & \\
\hline household deposits & 0.3448 & 0.1951 & 1 & & & & \\
\hline financial assets & 0.2301 & 0.2301 & 0.209 & 1 & & & \\
\hline poverty incidence & -0.2516 & -0.0827 & -0.2595 & -0.0973 & 1 & & \\
\hline degree of poverty & -0.3489 & -0.2533 & -0.2291 & -0.1568 & 0.2794 & 1 & \\
\hline married & 0.0367 & 0.1009 & -0.0133 & -0.0076 & 0.0315 & -0.016 & 1 \\
\hline
\end{tabular}


Table 4. The effect of marriage on the incidence of poverty: logit model.

\begin{tabular}{|c|c|c|c|c|}
\hline & (1) & (2) & (3) & (4) \\
\hline Marriage or not & $\begin{array}{l}0.2680^{* * *} \\
(0.0774)\end{array}$ & $\begin{array}{l}0.2807^{\star * *} \\
(0.0901)\end{array}$ & & \\
\hline consumption of marriage & & & $\begin{array}{c}0.0000 \\
(0.0000)\end{array}$ & $\begin{array}{c}0.0000 \\
(0.0000)\end{array}$ \\
\hline Community type & & $\begin{array}{c}-0.3384^{* * *} \\
(0.0481)\end{array}$ & & $\begin{array}{l}-0.2470 \\
(0.2575)\end{array}$ \\
\hline Annual income of household & & $\begin{array}{c}-0.0000^{\star * *} \\
(0.0000)\end{array}$ & & $\begin{array}{c}-0.0000^{* * *} \\
(0.0000)\end{array}$ \\
\hline Annual consumption of household & & $\begin{array}{l}0.0000^{* * *} \\
(0.0000)\end{array}$ & & $\begin{array}{l}0.0000^{* * *} \\
(0.0000)\end{array}$ \\
\hline household deposits & & $\begin{array}{c}-0.0000^{* * *} \\
(0.0000)\end{array}$ & & $\begin{array}{c}-0.0000^{* * *} \\
(0.0000)\end{array}$ \\
\hline Financial assets & & $\begin{array}{l}-0.0000 \\
(0.0000)\end{array}$ & & $\begin{array}{l}-0.0000 \\
(0.0000)\end{array}$ \\
\hline Provincial code & NO & YES & NO & YES \\
\hline Constant term & $\begin{array}{c}-0.3617^{\star * *} \\
(0.0177)\end{array}$ & $\begin{array}{c}0.4769 \\
(1.4162)\end{array}$ & $\begin{array}{l}-0.0756 \\
(0.1028)\end{array}$ & $\begin{array}{l}1.0683^{* * *} \\
(0.2930)\end{array}$ \\
\hline$N$ & 13946 & 13022 & 619 & 570 \\
\hline
\end{tabular}

Note: Standard errors in parentheses: ${ }^{*}<0.1,{ }^{* *} \mathrm{p}<0.05,{ }^{* * *} \mathrm{p}<0.01$.

explanatory variable, while the model (3)-model (4) takes the total marriage consumption as the core explanatory variable. Both regress by gradually controlling other variables and then we analyze the results.

The data of model (1) and model (2) in Table 4 shows that the selection of control variables has no significant influence on the positive and negative results of the estimation results and the significance, which reflects the robustness of the estimation results from the side. The basic conclusion of the two is: after controlling family annual income, family annual consumption, household deposits, family financial assets, family community types, and regional fixed effects, family marital events will increase the likelihood of families becoming poor households. Specifically, in contrast to families without a marriage event, if the family has a marriage event, the probability of the family becoming a poor household will increase by $28.7 \%$. This conclusion further validates the phenomenon of "marriage lead to poverty". Considering whether this is the effect of the total consumption of marriage, the results of Models (3)-(4) in Table 4 indicate that the coefficient is positive, but it does not pass the significance test.

\section{The effect of marriage on the degree of poverty of family}

Next, we examine the effect of marriage on household poverty intensity. Table 5 Models (1)-(3) examine the effect of marriage events in the family on the 
Table 5. The effect of marriage on the degree of poverty: OLS model.

\begin{tabular}{|c|c|c|c|c|c|c|}
\hline & (1) & (2) & (3) & $(4)$ & (5) & (6) \\
\hline \multirow[t]{2}{*}{ Marriage or not } & $-0.0220^{*}$ & $-0.0278^{\star * \star}$ & $-0.0338^{\star * *}$ & & & \\
\hline & $(0.0117)$ & $(0.0102)$ & $(0.0098)$ & & & \\
\hline \multirow[t]{2}{*}{ consumption of marriage } & & & & $-0.0000^{\star * \star}$ & $-0.0000^{\star *}$ & -0.0000 \\
\hline & & & & $(0.0000)$ & $(0.0000)$ & $(0.0000)$ \\
\hline \multirow[t]{2}{*}{ Community type } & & $-0.2801^{\star * *}$ & $-0.2823^{* * *}$ & & $-0.3189^{* * *}$ & $-0.3191^{\star * *}$ \\
\hline & & $(0.0051)$ & $(0.0052)$ & & $(0.0262)$ & $(0.0264)$ \\
\hline \multirow[t]{2}{*}{ Annual income of household } & & $-0.0000^{\star * \star}$ & $-0.0000^{\star * \star}$ & & $-0.0000^{\star * *}$ & $-0.0000^{\star * *}$ \\
\hline & & $(0.0000)$ & $(0.0000)$ & & $(0.0000)$ & $(0.0000)$ \\
\hline \multirow[t]{2}{*}{ Annual consumption of household } & & $-0.0000^{* * *}$ & $-0.0000^{* * *}$ & & -0.0000 & -0.0000 \\
\hline & & $(0.0000)$ & $(0.0000)$ & & $(0.0000)$ & $(0.0000)$ \\
\hline \multirow[t]{2}{*}{ household deposits } & & $-0.0000^{\star * *}$ & $-0.0000^{* * *}$ & & 0.0000 & 0.0000 \\
\hline & & $(0.0000)$ & $(0.0000)$ & & $(0.0000)$ & $(0.0000)$ \\
\hline \multirow[t]{2}{*}{ Financial assets } & & -0.0000 & 0.0000 & & -0.0000 & -0.0000 \\
\hline & & $(0.0000)$ & $(0.0000)$ & & $(0.0000)$ & $(0.0000)$ \\
\hline Provincial code & NO & NO & YES & NO & NO & YES \\
\hline \multirow[t]{2}{*}{ Constant term } & $0.4744^{\star * *}$ & $0.6463^{* * *}$ & $0.7536^{\star * *}$ & $0.4770^{\star * *}$ & $0.6071^{\star * *}$ & $0.5545^{\star *}$ \\
\hline & $(0.0026)$ & $(0.0035)$ & $(0.2377)$ & $(0.0150)$ & $(0.0188)$ & $(0.2341)$ \\
\hline $\mathrm{N}$ & 13405 & 12544 & 12544 & 598 & 558 & 558 \\
\hline $\mathrm{R} 2$ & 0.0002 & 0.3072 & 0.3546 & 0.0121 & 0.2729 & 0.3614 \\
\hline
\end{tabular}

Note: Standard errors in parentheses: ${ }^{*}<0.1,{ }^{* *} \mathrm{p}<0.05,{ }^{* *} \mathrm{p}<0.01$.

dependent variables, and Table 5 models (4)-(5) verify the effect of the total consumption of marriage on the dependent variable.

Table 5 Models (1)-(3) after controlling other variables step by step, the positive and negative characteristics of the core key variable "Marriage or not" and their significance have not changed significantly. This shows that marriage events in the family are negatively related to family poverty, and the results are significant and robust. Specifically, under the control of other factors, in contrast to families without a marriage event, if the family has a marriage event, the degree of family's poverty will fall roughly by a standard deviation of 0.034 . In other words, there is a marriage incident that will help improve the poverty intensity of the family. The results of table models (4)-(6) also show that the higher the total consumption of marriage, the lower the degree poverty of the family. The possible explanation for the above conclusions is that there is sample selectivity bias. If the family is too poor, the marriage is out of reach for them.

\section{Conclusions and Inspiration}

China's bride price of marriage has skyrocketed, and the demographic and social consequences of high bride price of marriage have attracted widespread atten- 
tion. Around the issue of abnormally high marital consumption, the academic community has also conducted some qualitative research. In this paper, we use the cross-sectional data from the China Family Panel Survey (CFPS) in 2014 to analyze the effect of marriage events and marriage consumption on household poverty.

The main conclusions of this paper are as follows: First, under the control of other factors unchanged, in contrast to families without a marriage event, if the family has a marriage event, the probability of the family becoming a poor household will increase by $28.7 \%$. This conclusion further validates the phenomenon of "Marriage leads to poverty". Second, if there is a marriage in the family, the higher the marriage consumption, the lower the family poverty. This may be due to sample selectivity bias. Marriage is more likely to occur in families with better living conditions.

The conclusions of this study lead to the following discussions and reflections: Abnormal high-marriage consumption is actually the phenomenon of exploitation between families and between generations. The serious marriage burden it brings to the family cannot be ignored. The bride price of marriage has become a way for newlyweds to exploit their parents. While the newly-married couples enjoy a new life brought to them by the high bride price of marriage, the heavy bride price burden has forced their parents to face the tragic situation of carrying debt and no one to support them. The formation of the high bride price of marriage has deep social roots. However, in essence, it is an abnormal human feeling. It is an alienation of human feeling. It is not an inevitable result of economic and social development. It is a tool choice for people to face competition under the confusion of value. It is necessary to make a strong counterattack against this old-fashioned marriage. We must actively guide people to change their traditional concepts, establish a correct concept of marriage, and resist the intrusion of bad customs. At the same time, it is necessary to formulate relevant laws and regulations, appropriately restrict the excessive bride price of marriage, and effectively prevent poverty caused by marriage.

There are certain limitations in this paper. First, cross-section data is used in this paper, and causal identification of marriage and family poverty has not yet been made clean. For example, the problem of sample selective bias cannot be resolved. Second, due to the limitations of the data, it is not possible to specifically identify the difference in the incidence of family poverty in urban households and rural households in the face of high-marriage consumption. Finally, due to data problems, this article does not explain the mechanism in further detail.

\section{Conflicts of Interest}

The authors declare no conflicts of interest regarding the publication of this paper.

\section{References}

[1] Chen, X.Y. (2014) The Influence of High Value Gift in Rural Marriage. Reform and 
Opening, No. 24, 48-49.

[2] He, S.H. (2017) Currency Going to the Countryside and Derangement of Values: Concurrently on the Formation of the Valuable Ceremony and Its Social Foundations. Chinese Youth Studies, No. 9, 42-48.

[3] Wang, X.L. and Alkire, S. (2009) Multidimensional Poverty Measurement in China: Estimation and Policy Implications. Chinese Rural Economy, No. 12, 4-10.

[4] Zhu, Z.H. (2017) A Comparative Study on the Regional Characteristics of Rural Bride Price of Marriage. Contemporary Youth Studies, No. 4, 61-66. 